\title{
Fenofibrate inhibits tumour intravasation by several independent mechanisms in a 3-dimensional co-culture model
}

\author{
CHI HUU NGUYEN ${ }^{1}$, NICOLE HUTTARY ${ }^{2}$, ATANAS G. ATANASOV ${ }^{3,4}$, WARANYA CHATUPHONPRASERT ${ }^{1,5}$, \\ STEFAN BRENNER ${ }^{1}$, ADRYAN FRISTIOHADY ${ }^{1,2,6}$, JUNLI HONG ${ }^{2,3,7}$, SERENA STADLER ${ }^{2}$, \\ SILVIO HOLZNER ${ }^{2}$, DANIELA MILOVANOVIC ${ }^{2}$, VERENA M. DIRSCH ${ }^{3}$, BRIGITTE KOPP ${ }^{3}$, \\ PHILIPP SAIKO $^{8}$, LISELOTTE KRENN ${ }^{3}$, WALTER JÄGER ${ }^{1}$ and GEORG KRUPITZA ${ }^{2}$ \\ ${ }^{1}$ Department of Clinical Pharmacy and Diagnostics, University of Vienna; ${ }^{2}$ Clinical Institute of Pathology, \\ Medical University of Vienna; ${ }^{3}$ Department of Pharmacognosy, University of Vienna, Vienna, Austria; \\ ${ }^{4}$ Institute of Genetics and Animal Breeding of the Polish Academy of Sciences, Jastrzebiec, Poland; ${ }^{5}$ Faculty of Medicine, \\ Mahasarakham University, Mahasarakham, Thailand; ${ }^{6}$ Faculty of Pharmacy, Halu Oleo University, Kendari, Indonesia; \\ ${ }^{7}$ School of Pharmacy, Nanjing Medical University, Nanjing, Jiangsu, P.R. China; ${ }^{8}$ Department of Medical \\ and Chemical Laboratory Diagnostics, Medical University of Vienna, Vienna, Austria
}

Received December 3, 2016; Accepted January 16, 2017

DOI: 10.3892/ijo.2017.3956

\begin{abstract}
Lymph node metastasis of breast cancer is a clinical marker of poor prognosis. Yet, there exist no therapies targeting mechanisms of intravasation into lymphatics. Herein we report on an effect of the antidyslipidemic drug fenofibrate with vasoprotective activity, which attenuates breast cancer intravasation in vitro, and describe the potential mechanisms. To measure intravasation in a 3-dimensional co-culture model MDA-MB231 and MCF-7 breast cancer spheroids were placed on immortalised lymphendothelial cell (LEC) monolayers. This provokes the formation of circular chemorepellent induced defects (CCIDs) in the LEC barrier resembling entry ports for the intravasating tumour. Furthermore, the expression of adhesion molecules ICAM-1, CD31 and FAK was investigated in LECs by western blotting as well as cellcell adhesion and NF- $\kappa \mathrm{B}$ activity by respective assays. In MDA-MB231 cells the activity of CYP1A1 was measured by EROD assay. Fenofibrate inhibited CCID formation in the MDA-MB231/LEC- and MCF-7/LEC models and the activity of NF- $\mathrm{KB}$, which in turn downregulated ICAM-1 in LECs and the adhesion of cancer cells to LECs. Furthermore, CD31 and the activity of FAK were inhibited. In MDA-MB231 cells, fenofibrate attenuated CYP1A1 activity. Combinations with other FDA-approved drugs, which reportedly inhibit different ion
\end{abstract}

Correspondence to: Professor Georg Krupitza, Institute of Clinical Pathology, Medical University of Vienna, Waehringer Guertel 18-20, A-1090 Vienna, Austria

E-mail: georg.krupitza@meduniwien.ac.at

Key words: fenofibrate, adhesion, ICAM-1, FAK, breast cancer intravasation, 3D-model channels, attenuated CCID formation additively or synergistically. In summary, fenofibrate inhibited NF- $\mathrm{KB}$ and ICAM-1, and inactivated FAK, thereby attenuating tumour intravasation in vitro. A combination with other FDA-approved drugs further improved this effect. Our new concept may lead to a novel therapy for cancer patients.

\section{Introduction}

The colonisation of distant organs by disseminating breast cancer cells is the main cause for cancer death in women. Targeting neo-vascularisation with tailored drugs may prevent the spreading of those cancer entities that expand through the blood stream. In the early phases of breast cancer metastasis however, cancer cells disperse through lymphatics. Before metastases colonise organs the sentinel and post-sentinel lymph nodes fill up with breast cancer cells and hence, the axillary lymph node status is a major prognostic marker for clinical outcome (1). As blocking of intravasation would improve prognosis, understanding of mechanistic details of breast cancer intravasation into lymphatic vessels is crucial to develop treatment strategies preventing lymph node metastasis. Although prognostic markers exist, no predictive markers have been identified to date, which could be targeted to combat intravasation. Nevertheless, a few mechanisms supporting the transmigration of cancer cells through the lymphatic barrier were described (2-4). Intravasation is an interplay among cancer cells and the endothelial barrier. Importantly, not only cancer cells play an active role in this process but also lymph endothelial cells (LECs) remarkably contribute to lymph node metastasis i.e. by providing niches for cancer cell settlement (5). To further study the role of LECs at an early metastatic step, a quantitative assay based on a three-dimensional (3D) cell model was developed consisting of breast cancer spheroids placed on top of lymphendothelial monolayers, which resembles the contact zone between the 
tumour and lymphatics (6). This 3D in vitro model is validated in scid mice and in tissue sections of human patients (7) and was here utilised to measure tumour cell-induced retraction of LECs, which enables cancer cells to transmigrate the lymphatic barrier. Focussing on the regulation and maintenance of the endothelial barrier function several mechanisms of LECs, which are relevant to withstand tumour intravasation, were found to become weakened by signals of adjacent cancer cells $(3,4)$. Notably, LECs - upon activation of specific receptors - 'invite' cancer cells to intravasate by reducing the resilience of the endothelial wall $(2,8,9)$ through a process called endothelial-to-mesenchymal transition. In turn, LECs acquire a migratory phenotype and open gates for cancer cell transit as a rate limiting step of lymph node metastasis (7). Hence, strengthening vascular integrity and tone may improve resistance to intravasating cancer cells.

As a pro-migratory mechanism ion channels modulate adhesion and mobility of tumour cells and their dysregulation is currently discussed to play a role in cancer metastasis (10). For example, the overexpression of voltage gated $\mathrm{K}^{+}$channels was observed in breast-, colon- and prostate cancer and medullablastoma $(11,12)$ and their inhibition attenuates neuroblastoma and endothelial cell migration $(13,14)$. Consistently, the $\mathrm{Na}^{+} / \mathrm{K}^{+}$-ATPase inhibitor ouabain (also known as g-strophanthin) attenuates medullablastoma cell migration and the localisation of Tyr397-phosphorylated FAK to lammelipodia (15). Furthermore, the voltage gated $\mathrm{K}^{+} \mathrm{v} 1.2$ channel induces directional migration of mesenchymal bone marrow or $\mathrm{CHO}$ cells through phosphorylation of Tyr397-FAK (16) as well as wound healing in an animal model (17). The antidyslipidemic drug fenofibrate closes $\mathrm{K}^{+}$ATP channels $(18,19)$ and voltage gated $\mathrm{K}^{+}$channels $(20)$, enhances endothelial barrier function and integrity $(5,21)$ and is therefore, vasoprotective.

Furthermore, fenofibrate exhibits anticancer effects (22). Independent of $\mathrm{K}^{+}$channel inhibition, fenofibrate binds to and activates peroxisome proliferator-activated protein alpha $(\operatorname{PPAR} \alpha)$, which directly binds to the I $\kappa \mathrm{B} \alpha$ promoter, induces $\mathrm{I} \kappa \mathrm{B} \alpha$ protein expression (23) and in turn inhibits $\mathrm{NF}-\kappa \mathrm{B}(24,25) . \mathrm{NF}-\kappa \mathrm{B}$ plays a role in tumour progression and intravasation through lymphendothelial barriers $(3,4)$. Hence, both activities of fenofibrate, PPAR $\alpha$ activation, which was shown to suppress cancer progression $(26,27)$, as well as $\mathrm{K}^{+}$channel inhibition $(10,18,20)$ may attenuate adhesion and cell mobility $(28,29)$. In the clinic fenofibrate is used to eliminate triglycerides from the blood stream (30), thereby reducing hypercholesterolemia and the risk of cardiovascular diseases. Therefore, fenofibrate and a few more clinically used drugs with reported ion channel inhibitory properties were here investigated regarding their potential activities inhibiting triple-negative (MDA-MB231) and estrogen receptor-positive (MCF-7) breast cancer cell intravasation in vitro. Such drugs would be directly available to patients.

\section{Materials and methods}

Antibodies and reagents. Polyclonal rabbit anti-focal adhesion kinase (FAK) and polyclonal rabbit anti-phospho-Tyr397FAK were from Cell Signaling (Danvers, MA, USA). Polyclonal goat anti-CD54 (ICAM-1) antibody was from
R\&D System (clone BBA-17, Minneapolis, MN, USA) and monoclonal anti- $\beta$-actin from Sigma (Munich, Germany). Monoclonal mouse anti-CD31 (JC70A), polyclonal rabbit anti-mouse, anti-goat and anti-rabbit IgGs were from Dako (Glostrup, Denmark).

The I $\kappa \mathrm{B} \alpha$ phosphorylation inhibitor (E)-3-[(4methylphenylsulfonyl]-2-propenenitrile (Bay11-7082) was purchased from Biomol (Hamburg, Germany). Bepridil hydrochloride (bepridil), niflumic acid, fenofibrate, cisapride monohydrate (cisapride), primaquine, proadifen, digoxin, chlorotoxin and ouabain octahydrate (ouabain) were from Sigma. Dyclonine was from Abcam (Cambridge, UK).

Cell culture. Human MDA-MB231 and MCF-7 breast cancer cells were purchased from the American Type Culture Collection (ATCC, Rockville, MD, USA) and grown in MEM medium supplemented with $10 \%$ foetal calf serum (FCS), $1 \%$ penicillin/streptomycin (PS) and $1 \%$ non-essential amino acids (Gibco/Invitrogen, Karlsruhe, Germany). Telomerase immortalized human lymph endothelial cells (LECs) were grown in EGM2 MV (Clonetics CC-4147, Allendale, NJ, USA). The cells were kept at $37^{\circ} \mathrm{C}$ in a humidified atmosphere containing $5 \% \mathrm{CO}_{2}$. For CCID formation assays, LECs were stained with CellTracker ${ }^{\mathrm{TM}}$ green purchased from Invitrogen (Karlsruhe, Germany).

Spheroid formation. MDA-MB231 cells (input of 6,000 cells per spheroid) and MCF-7 cells (input of 3,000 cells per spheroid) were transferred to $30 \mathrm{ml}$ serum-free MEM medium containing $6 \mathrm{ml}$ of a $1.6 \%$ methylcellulose solution $(0.3 \%$ final concentration; cat. no.: M-512, 4000 centipoises; SigmaAldrich, Munich, Germany). Cell suspension (150 $\mu \mathrm{l})$ were transferred to each well of a 96-well plate (Greiner Bio-one, Cellstar 650185, Kremsmünster, Austria) to allow spheroid formation within $48 \mathrm{~h}$.

CCID (circular chemorepellent induced defect) assay. In this assay the sizes of the cell-free areas (CCIDs), which are formed in the endothelial monolayer directly underneath the tumour spheroids, were measured (7). MDA-MB231 spheroids were washed in PBS and transferred to CellTracker (green)-stained LEC monolayers that were seeded into 24-well plates (Costar 3524, Sigma-Aldrich) in $1 \mathrm{ml}$ EGM2 MV medium. After $4 \mathrm{~h}$ of incubation, the CCID areas in the LEC monolayers underneath the MDA-MB231 spheroids were photographed using an Axiovert (Zeiss, Jena, Germany) fluorescence microscope to visualise CellTracker-stained LECs underneath the spheroids. CCID areas were calculated with the Zen Little 2012 (Zeiss). For each condition the CCID size of at least 25 spheroids (unless otherwise specified) was measured.

SDS gel electrophoresis and western blotting. LECs were grown in T-25 tissue culture flasks (Nunc, Roskilde, Denmark) to $80 \%$ confluence and then pre-treated with indicated clinical drugs or inhibitors for $0.5,1,2$ and $4 \mathrm{~h}$. Then, cells were processed for SDS gel electrophoresis and western blotting as described before (4). Chemo-luminescence was developed by Amersham ECL Prime kit (GE Healthcare, Freiburg, Germany) and detected using a Lumi-Imager F1 Workstation (Roche, Basel, Switzerland). Densitometry of the western blots 
was analysed with Image-J software (National Institutes of Health, Bethesda, MD, USA).

Ethoxyresorufin-O-deethylase (EROD) assay selective for CYP1A1 and CYP1A2 activity. MDA-MB231 cells were grown in phenol red-free DMEM/F12 medium (Gibco, Karlsruhe, Germany) containing 10\% FCS and 1\% PS (Invitrogen, Karlsruhe, Germany). Before treatment, the cells were transferred to DMEM/F12 medium supplemented with $10 \%$ charcoal-stripped FCS (PAN Biotech, Aldenbach, Germany) and $1 \%$ PS. After $24 \mathrm{~h}$ of treatment CYP1A1 activity was measured with minor modifications as previously described (31). Briefly, ethoxyresorufin (final concentration $5.0 \mu \mathrm{M}$, Sigma-Aldrich) was added and $0.4 \mathrm{ml}$ aliquots of the medium were sampled after $180 \mathrm{~min}$ and the formation of resorufin was analysed by spectrofluorometry (PerkinElmer LS50B, Waltham, MA, USA) with an excitation wavelength of $530 \mathrm{~nm}$ and an emission wavelength of $585 \mathrm{~nm}$. The pan-CYP inhibitor proadifen (Sigma-Aldrich) was used as a positive control.

$N F-\kappa B$ transactivation assay. The transactivation of a NF- $\kappa \mathrm{B}-$ driven luciferase reporter was quantified in HEK293/NF- $\kappa$ B-luc cells (Panomics, RC0014, Fremont, CA, USA) as previously described (32). In brief, cells were maintained at $37^{\circ} \mathrm{C}$ and $5 \%$ $\mathrm{CO}_{2}$, humidified atmosphere in Dulbecco's modified Eagle's medium (DMEM; Lonza, Basel, Switzerland) supplemented with $2 \mathrm{mM}$ glutamine, $100 \mu \mathrm{g} / \mathrm{ml}$ hygromycin $\mathrm{B}, 100 \mathrm{U} / \mathrm{ml}$ benzylpenicillin, $100 \mu \mathrm{g} / \mathrm{ml}$ streptomycin, and $10 \%$ FCS. One day before the experiments the cells were stained in serum-free medium supplemented with $2 \mu \mathrm{M}$ CellTracker Green CMFDA (C2925; Invitrogen) for $1 \mathrm{~h}$. Then, cells were reseeded in 96-well plates at a density of $4 \times 10^{4}$ cells/well in phenol redfree and FCS-free DMEM overnight, and pre-treated with the indicated compounds for $30 \mathrm{~min}$ prior to stimulation with $2 \mathrm{ng} / \mathrm{ml} \mathrm{TNF} \alpha$ for $4 \mathrm{~h}$. The final concentration of DMSO in the experiments was $0.1 \%$ or lower and an equal concentration of DMSO was used as control. After cell lysis the luminescence of the firefly luciferase and the fluorescence of the CellTracker Green CMFDA were quantified on a GeniosPro plate reader (Tecan, Grodig, Austria). The luciferase-derived signal from the NF- $\mathrm{kB}$ reporter was normalized by the CellTracker Green CMFDA derived fluorescence to account for differences in the cell number. The known NF-кB inhibitor parthenolide (SigmaAldrich, Vienna, Austria) was used as a positive control.

Adhesion assay. MDA-MB231 (40,000 cells/well) were seeded in serum-free medium (DMEM containing 0.5\% BSA, $2 \mathrm{mM}$ $\mathrm{CaCl}_{2}$ and $2 \mathrm{mM} \mathrm{MgCl}_{2}$ ). Then 500X CellTracker (500X CellTracker Solution from CytoSelect ${ }^{\mathrm{TM}}$ Tumor-endothelium Adhesion Assay from Cell Biolabs, Inc., San Diego, CA, USA, CBA-215) was added to the cell suspension (2 $\mu \mathrm{l}$ CellTracker to $1 \mathrm{ml}$ suspension), incubated for $1 \mathrm{~h}$ at $37^{\circ} \mathrm{C}$ and centrifuged at $1,000 \mathrm{rpm}$ for $2 \mathrm{~min}$. Then the medium was aspirated, the cell pellet was washed $\mathrm{x} 3$ with serum-free medium (DMEM containing $0.5 \% \mathrm{BSA}, 2 \mathrm{mM} \mathrm{CaCl}{ }_{2}$ and $2 \mathrm{mM} \mathrm{MgCl}_{2}$ ) and then the cell pellet was re-suspended in EGM2 MV medium. The CellTracker-stained MDA-MB231 cell suspension was treated either with Bay11-7082 as a positive control, indicated compounds, or DMSO and incubated for $10 \mathrm{~min}$ at room temperature. After incubation, the medium was aspirated from the 48-well plate and $200 \mu \mathrm{l}$ of the pre-treated MDA-MB231 cell suspension was added to LECs grown in monolayers and incubated for $30 \mathrm{~min}$ at $37^{\circ} \mathrm{C}$. Then the medium was aspirated and cells were washed $3 \mathrm{x}$ with $250 \mu \mathrm{l} 1 \mathrm{X}$ Wash Buffer (10X Wash Buffer was from CytoSelect Tumor-endothelium Adhesion Assay). Before the third wash, cells were inspected for morphological changes under the microscope. After the final wash the plate was tapped on a flint-free paper towel and $150 \mu \mathrm{l}$ of $1 \mathrm{X}$ Lysis Buffer (4X Lysis Buffer were from CytoSelect Tumor-endothelium Adhesion Assay) was added to each well and cells were lysed by the shearing forces through a pipette tip. Lysate $(100 \mu \mathrm{l})$ was transferred to 96 -well blackwall clear bottom plates (Nunc, Thermo Scientific, Rochester, NY, USA) and the fluorescence was measured with a fluorescence plate reader at $485 / 530 \mathrm{~nm}$.

Statistical analysis. For statistical analyses Excel 2013 software and Prism 6 software package (GraphPad, San Diego, CA, USA) were used. The values were expressed as mean \pm SEM and the Student's t-test and ANOVA with Tukey's post-test was used to compare differences between control samples and treatment groups as well as difference among treatment groups. Statistical significance level was set to $\mathrm{P}<0.05$.

\section{Results}

Fenofibrate inhibits $N F-\kappa B, I C A M-1, F A K$, adhesion and CCID formation in LECs. Fenofibrate inhibited TNF $\alpha$-induced NF- $\mathrm{KB}$ activation (Fig. 1A) and transiently downregulated expression of the adhesion molecules ICAM-1 and CD31 in LECs (Fig. 1B). In addition, Bay11-7802 (a specific NF- $\mathrm{BB}$ inhibitor) suppressed ICAM-1 (Fig. 1C) and both compounds inhibited the adhesion of MDA-MB231 cells to LECs (Fig. 1D), which is a prerequisite for intravasation and CCID formation (3). Accordingly, fenofibrate attenuated CCID formation in the MDA-MB231/LEC model (Fig. 1E) and in the MCF-7/LEC model (Fig. 1F). The inhibition of CCID formation by fenofibrate was achieved at concentrations as low as $5 \mu \mathrm{M}$. However, the inhibition of NF- $\kappa \mathrm{B}$ and of cell adhesion was observed at higher concentrations indicating that also another mechanism must have been involved in the CCID- inhibitory effect of fenofibrate. It was shown that fenofibrate inhibits cell migration and stabilises HUVEC barrier function, which is accompanied by the downregulation of FAK activity (5). FAK activity is required for cell-matrix adhesion and directional migration $(33,34)$ and adhesion and migration is also necessary for CCID formation (7). In LEC fenofibrate inhibited the phosphorylation of Tyr397-FAK (Fig. 1G), which is indicative for its activity.

Bona fide $K^{+}$channel inhibitors attenuate CCID formation. To investigate whether potassium channels contribute to CCID formation, the MDA-MB231/LEC model was treated with ouabain and digoxin, which are used to specifically inhibit $\mathrm{Na}^{+} / \mathrm{K}^{+}$-ATPase $(35,36)$. Ouabain and digoxin dose-dependently attenuated MDA-MB231-triggered CCID formation (Fig. 2A and B; respectively). Ouabain inhibits cell migration through inactivation of FAK (37) and also digoxin inhibits cell migration (38). Similarly, cisapride (a serotonin 5-HT 4 receptor agonist used to treat gastroesophageal reflux 


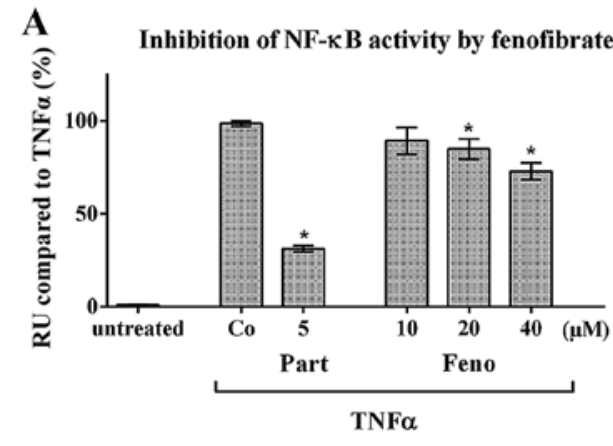

C

Bay11-7082

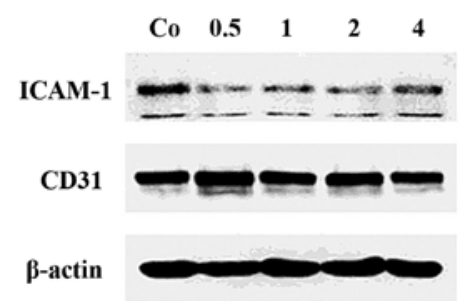

$\mathbf{E}$

Treatment of MDA-MB231/LEC model with fenofibrate

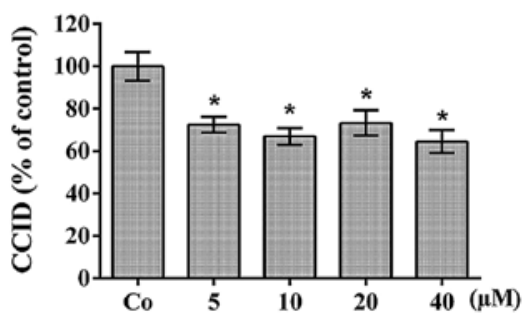

B

Fenofibrate

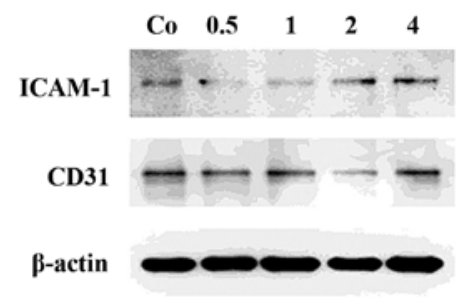

D

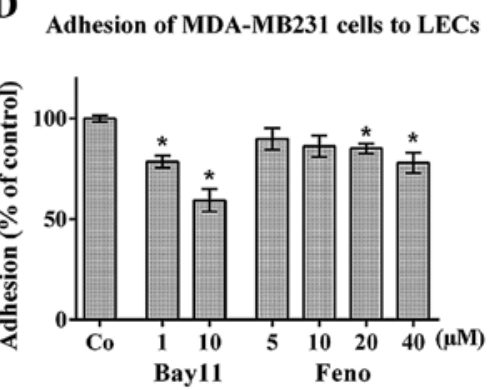

$\mathbf{F}$

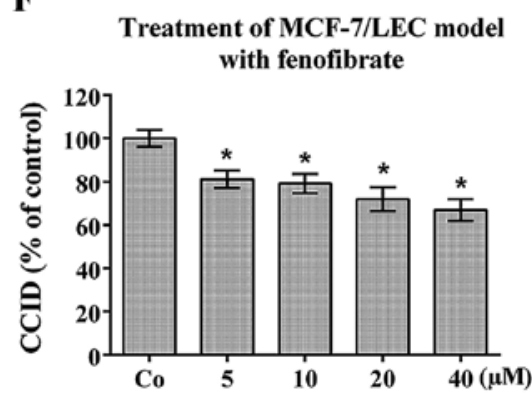

G

Fenofibrate

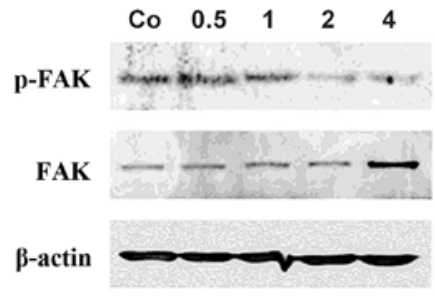

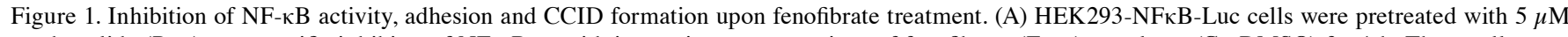
parthenolide (Part) as a specific inhibitor of NF- $\mathrm{kB}$ or with increasing concentrations of fenofibrate (Feno) or solvent (Co-DMSO) for $1 \mathrm{~h}$. Then, cells were stimulated with $2 \mathrm{ng} / \mathrm{ml}$ human recombinant TNF $\alpha$ for an additional $4 \mathrm{~h}$ when NF- $\mathrm{kB}$ activity was measured. Three independent experiments with 4 replicates were analysed. (B) LECs were grown to $\sim 80 \%$ confluence and then pretreated with solvent (Co) or $20 \mu \mathrm{M}$ fenofibrate or (C) $5 \mu \mathrm{M}$ Bay11-7082 as a specific inhibitor of NF-kB for 0.5, 1, 2 and $4 \mathrm{~h}$. Then, cells were lysed, proteins separated by SDS gel electrophoresis and subjected to western blotting using the indicated antibodies. Staining with Ponceau $\mathrm{S}$ and immunoblotting with anti- $\beta$-actin antibody controlled equal sample loading. (D) MDA-MB231 cells were pre-treated with Bay11-7082 (Bay11) or with increasing concentrations of fenofibrate, or solvent (Co) and then placed on confluent LEC monolayers, which were also pre-treated with respective compounds. After 30 min the adhesion of MDA-MB231 cells to LECs was measured as described in Materials and methods. Experiments were performed in triplicate. (E) MDA-MB231 spheroids or (F) MCF-7 spheroids were pre-treated for 30 min with solvent (Co) or the indicated fenofibrate concentrations. Then, spheroids were placed on top of LEC monolayers and co-cultivated for $4 \mathrm{~h}$ when CCIDs were analysed. Three independent experiments with at least 8 replicates were analysed. (G) LECs were grown to $\sim 80 \%$ confluence and then pretreated with solvent (Co) or fenofibrate for 0.5 , 1,2 and $4 \mathrm{~h}$ when cells were lysed, proteins separated by SDS gel electrophoresis and subjected to western blotting using the indicated antibodies. Error bars indicate means \pm SEM and asterisks significance ( $\mathrm{P}<0.05$; ANOVA together with Tukey's post-test).

disease) and primaquine (used to treat malaria through binding to Plasmodium DNA), which were both reported to inhibit hERG-K ${ }^{+}$channel $(39,40)$, inhibited MDA-MB231-triggered CCID formation (Fig. 2C and D; respectively) and MCF-7trigerred CCID formation (Fig. 2E and F; respectively). As the treatment with known $\mathrm{K}^{+}$ATPase- and hERG- $\mathrm{K}^{+}$channel inhibitors resulted in significant inhibition of CCID formation, it was concluded that the activity of $\mathrm{K}^{+}$channels contributes to breast cancer intravasation in vitro. Based on these results fenofibrate seems to inhibit CCID formation through inhibition 
A

Treatment of MDA-MB231/LEC model with ouabain

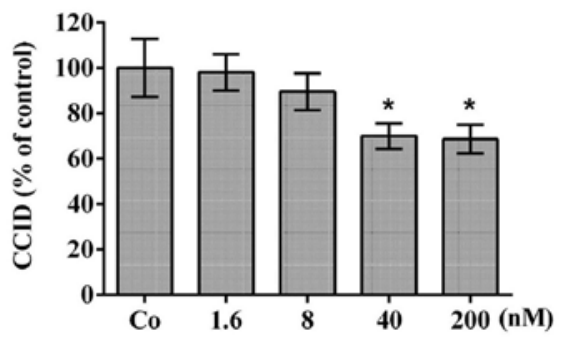

C

Treatment of MDA-MB231/LEC model with cisapride

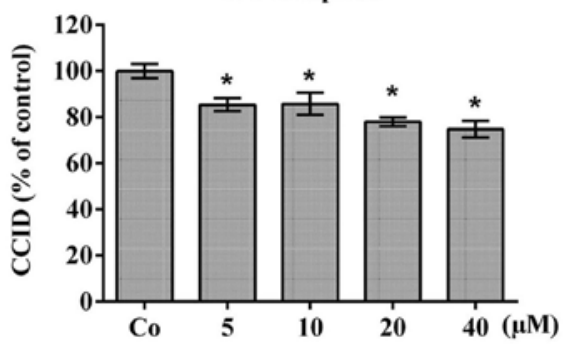

E

Treatment of MCF-7/LEC model with cisapride

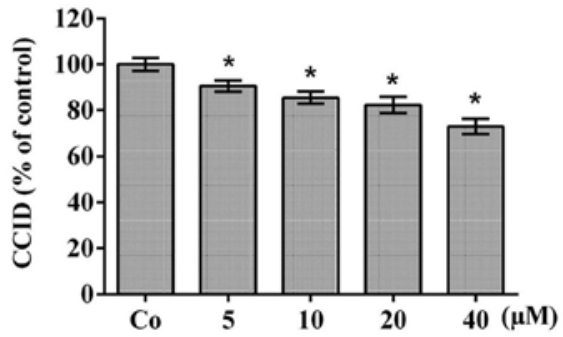

B

Treatment of MDA-MB231/LEC model with digoxin

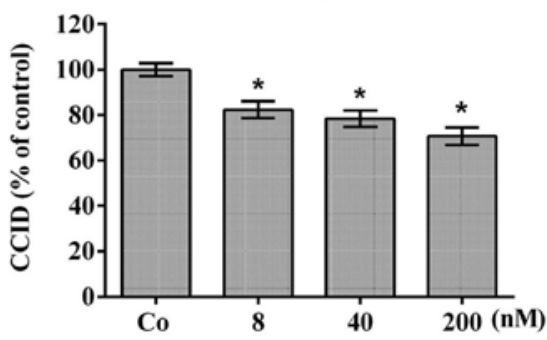

D

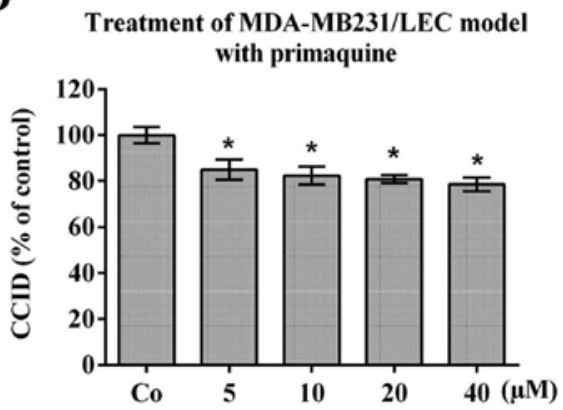

F

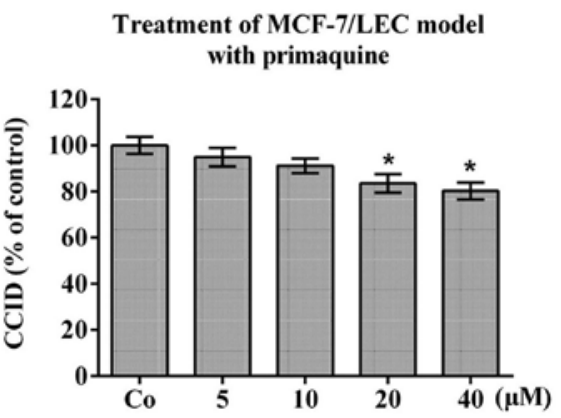

Figure 2. Inhibition of CCID formation in LEC monolayers by bona fide $\mathrm{K}^{+}$channel inhibitors and clinical drugs. (A-D) MDA-MB231 spheroids or (E and F) MCF-7 spheroids were pre-treated for 30 min with solvent (Co-DMSO) or the indicated concentrations of (A) ouabain, (B) digoxin, (C and E) cisapride, (D and F) primaquine. Then, spheroids were placed on top of LEC monolayers and co-cultivated for $4 \mathrm{~h}$ when CCIDs were measured. Three independent experiments with at least 8 replicates were analysed. Error bars indicate means \pm SEM and asterisks significance $(\mathrm{P}<0.05$; ANOVA together with Tukey's post-test).

of NF- $\mathrm{\kappa B}$ activity as well as of $\mathrm{K}^{+}$channels. Reportedly, the delayed rectifier $\mathrm{K}^{+} \mathrm{v} 2.1$ channel induces the phosphorylation of Tyr397-FAK (16,17). Therefore, fenofibrate may have inhibited FAK phosphorylation through inhibition of $\mathrm{K}^{+} \mathrm{v} 1.2$ channel. Furthermore, primaquine, but not cisapride inhibited the phosphorylation of Tyr397-FAK (data not shown).

Niflumic acid, dyclonine and bepridil hydrochloride inhibit CCID formation. As $\mathrm{K}^{+}$-channels, also $\mathrm{Cl}^{-}-\mathrm{Na}^{+}$, and $\mathrm{Ca}^{2+}$-channels are dis-regulated during carcinogenesis (10). Therefore, the 3D-models were treated with the reported $\mathrm{Cl}^{-}$-channel inhibitors chlorotoxin and niflumic acid $(41,42)$ (Fig. 3A, B and E, respectively), the $\mathrm{Na}^{+}$-channel inhibitor dyclonine (43) (Fig. 3C and F) and the $\mathrm{Ca}^{2+}$-channel inhibitor bepridil hydrochloride (44) (Fig. 3D and G), which inhibited MDA-MB231- and MCF-7- triggered CCID formation in LEC barriers.

Fenofibrate, primaquine, cisapride, dyclonine, bepridil and niflumic acid inhibit CYP1A1 in MDA-MB231 cells.
Intravasation is an interplay between tumour emboli and the vessel endothelium beneath. In the former experiments the effect of fenofibrate was investigated in LECs. Herein, the effect of fenofibrate and the other clinical drugs was studied in MDA-MB231 breast cancer cells. Recently, it was shown that MDA-MB231 cell intravasation depends on NF- $\mathrm{kB}$ - and CYP1A1-activity of the cancer cells $(4,45)$. Niflumic acid, bepridil and primaquine, but not dyclonine or cisapride, inhibited TNF $\alpha$-induced NF- $\kappa$ B activity in HEK293/NF- $\mathrm{kB}$-luc cells (Fig. 4A). Furthermore, the treatment of MDA-MB231 cells with fenofibrate, primaquine, dyclonine, bepridil, niflumic acid and cisapride significantly inhibited the formation of resorufin indicating the inhibition of CYP1A1 activity (tested by EROD assay; Fig. 4B). Hence, the here tested drugs also exerted their anti-intravasative properties by attenuating CYP1A1 activity in the tumour cells and some, additionally, by inhibiting NF- $\kappa$ B.

Drug combinations further reduce intravasation. The drugs at $20 \mu \mathrm{M}$ of fenofibrate, cisapride, primaquine, niflumic 
A

Treatment of MDA-MB231/LEC model with chlorotoxin

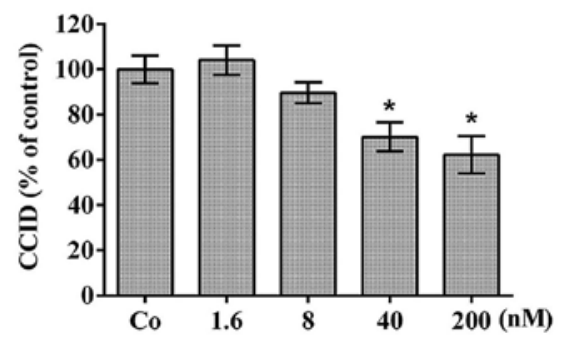

C

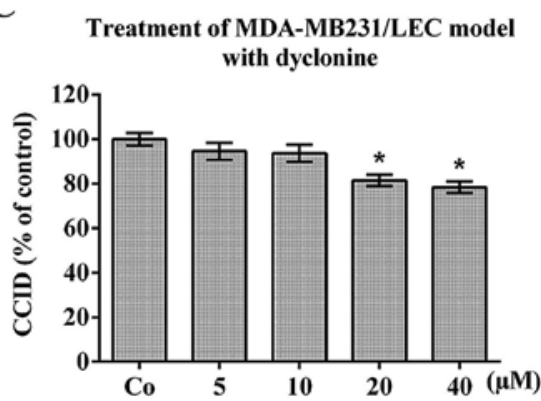

$\mathbf{E}$

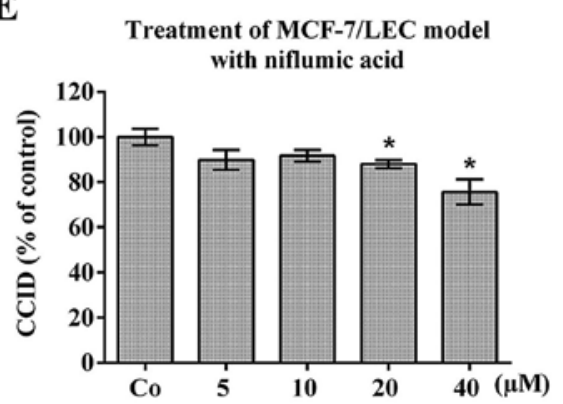

B

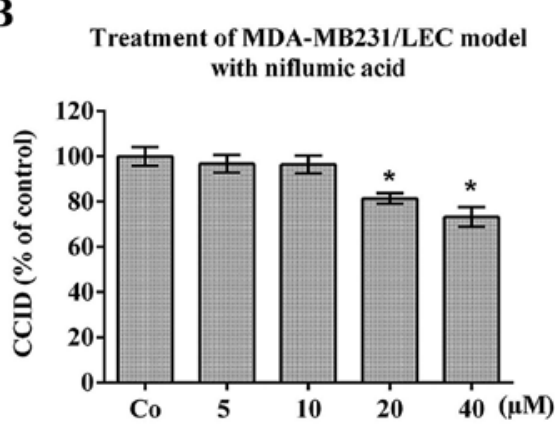

D

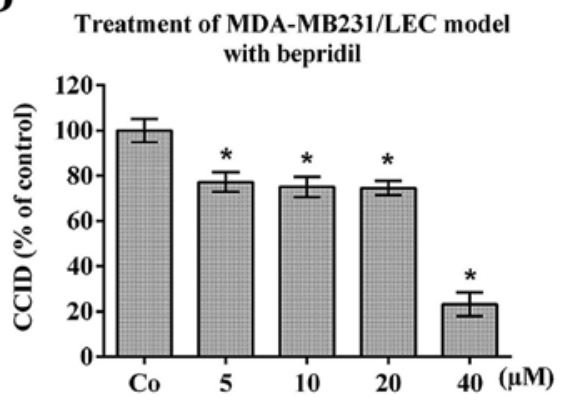

F
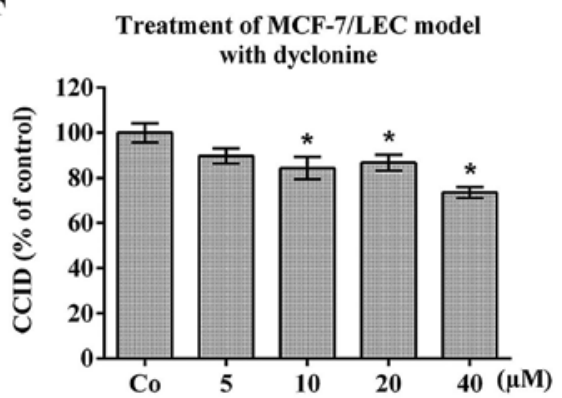

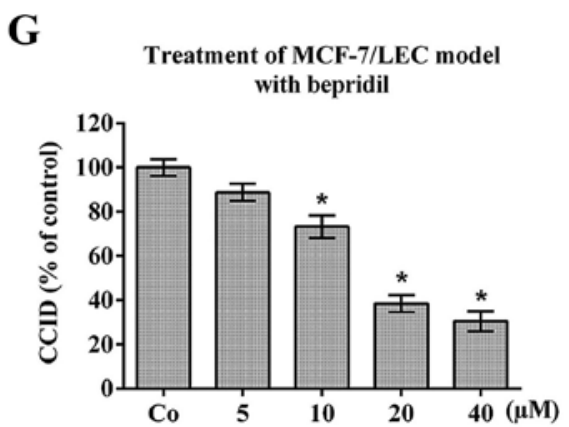

Figure 3. Inhibition of CCID formation in LEC monolayers by clinical drugs. (A-D) MDA-MB231 spheroids or (E-G) MCF-7 spheroids were pre-treated for 30 min with solvent (Co-DMSO) or the indicated concentrations of (A) chlorotoxin, (B and E) niflumic acid, (C and F) dyclonine and (D and G) bepridil. Then, spheroids were placed on top of LEC monolayers and co-cultivated for $4 \mathrm{~h}$ when CCIDs were measured. Three independent experiments with at least 8 replicates were analysed. Error bars indicate means \pm SEM and asterisks significance ( $\mathrm{P}<0.05$; ANOVA together with Tukey's post-test).

acid, bepridil and dyclonine acid inhibited CCID formation by $\sim 20 \%$. Therefore, we investigated whether drug combinations may improve the CCID-inhibitory effect. Combining only bona fide $\mathrm{K}^{+}$channel inhibitors or $\mathrm{K}^{+}$channel inhibitors together with the $\mathrm{Na}^{+}$channel inhibitor dyclonine did not exhibit improved effects (Table I). In contrast, the combinations of bepridil hydrochloride and primaquine, or bepridil hydrochloride and dyclonine, or bepridil hydrochloride and niflumic acid, or niflumic acid and cisapride, or niflumic acid and primaquine inhibited CCID formation additively. Synergistic effects were achieved when combining bepridil hydrochloride and cisapride, or bepridil hydrochloride and fenofibrate, or niflumic acid and fenofibrate, or niflumic acid and dyclonine (Fig. 5). Since different drug combinations resulted in additive, synergistic, or unchanged inhibition of CCID formation, this implicated that the treatment with these drugs affected intravasative mechanisms non-randomly.

We searched for potential drug-drug interactions (DDIs) such as between fenofibrate, cisapride, and niflumic acid, which are recorded in the data base of the-Austria-Codex Fachinformation (Oesterreichische Apotheker-Verlagsgesellschaft m.b.H., date of release: 01/09/2016) regarding known cross reactions. 
A

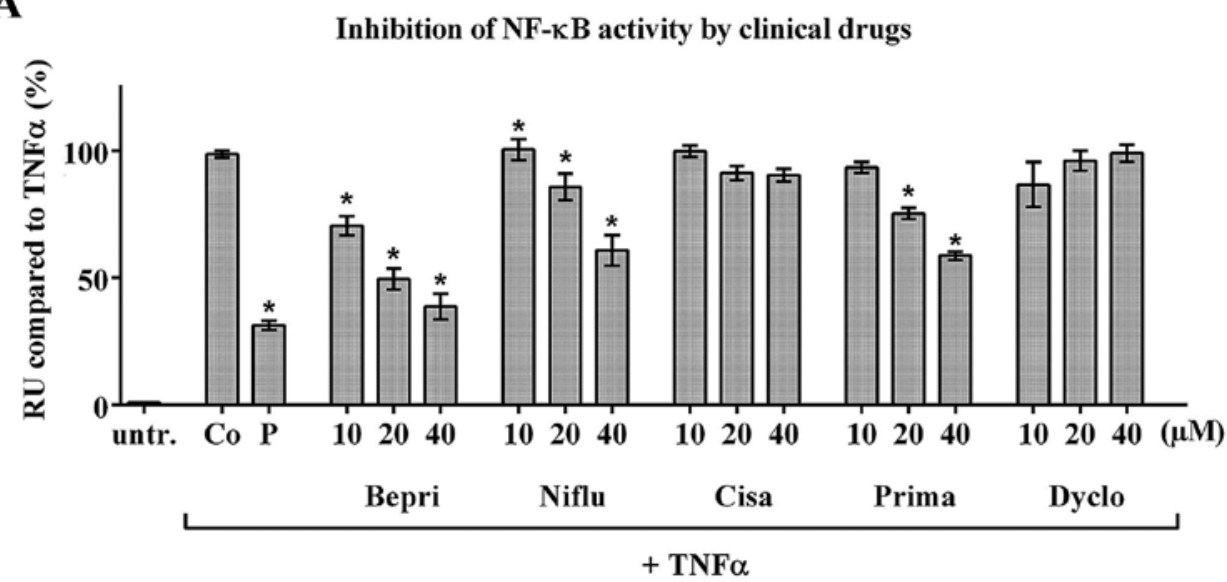

B

Inhibition of CYP1A1 activity in MDA-MB231 cells by clinical drugs

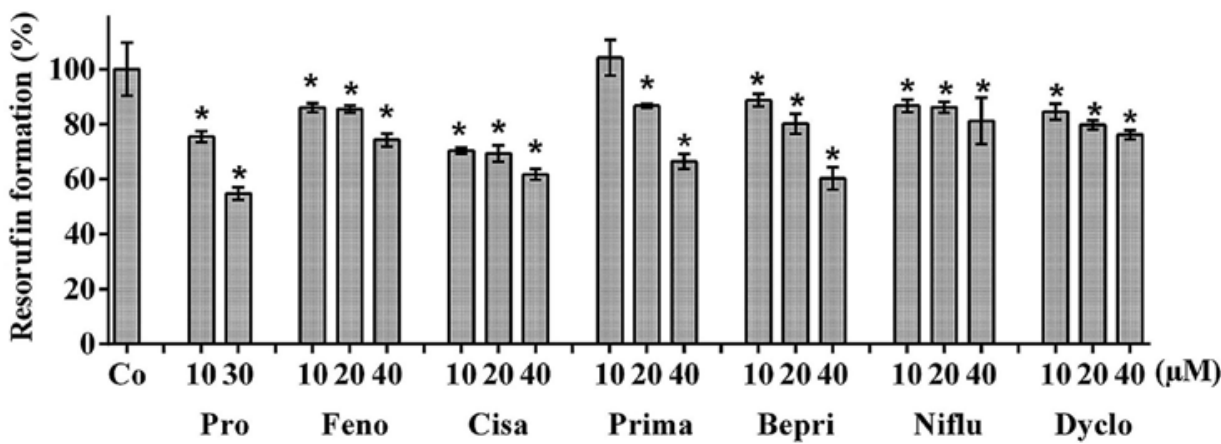

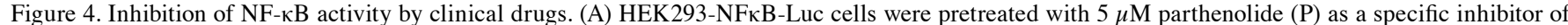
NF- $\mathrm{KB}$ or with increasing concentrations of the indicated drugs (bepridil-Bepri; niflumic acid-Niflu; cisapride-Cisa; primaquine-Prima; dyclonine-Dyclo) or solvent (DMSO-Co) for $1 \mathrm{~h}$. Then, cells were stimulated with $2 \mathrm{ng} / \mathrm{ml}$ human recombinant TNF $\alpha$ for an additional $4 \mathrm{~h}$ when NF-kB activity was measured or were left TNF $\alpha$-untreated (untr.). Three independent experiments with at least 4 replicates were analysed. Inhibition of CYP1A1 activity in MDA-MB231 cells by clinical drugs. (B) MDA-MB231 cells were treated with the indicated concentrations of clinical drugs (fenofibrate-Feno, etc.) or solvent. Ethoxyresorufin $(5 \mu \mathrm{M})$ was added and after $180 \mathrm{~min}$ the formation of resorufin was measured. The pan-CYP-inhibitor proadifen (Pro) was used as a control. Three independent experiments with at least 3 replicates were analysed. Error bars indicate means \pm SEM and asterisks significance ("P<0.05; ANOVA together with Tukey's post-test).

Moreover, DDIs between these drugs and standard chemotherapeutic drugs used in breast cancer were screened, yet no dangerous DDIs were retrieved. Bepridil, dyclonine, and primaquine were not listed as these drugs are not licensed in Austria and Germany.

\section{Discussion}

Adhesion of breast cancer cells to the LEC wall is obligatory to enable subsequent intravasation into the vessel lumen (3). It was shown that cancer cell adhesion (10) and adhesion of endothelial cells to monocytes depends on $\mathrm{K}^{+}$channel activity (46). Reportedly, the antidislypidemic and therefore, vasoprotective drug fenofibrate inhibits $\mathrm{K}^{+}$-ATPase and voltage gated $\mathrm{K}^{+}$channels $(19,20)$ and tumour invasivity $(5)$. As dysregulated ion channels assist tumour progression (10), this tempted us to investigate whether fenofibrate and other ion channel inhibitors that are in clinical use attenuate breast cancer cell intravasation. Fenofibrate modulates LEC adhesion (5) by activating PPAR $\alpha$ which in turn inhibits $\mathrm{NF}-\kappa \mathrm{B}(24,25)$ and by inhibiting $\mathrm{K}^{+}$channel activity $(20)$. Herein, we demonstrate a novel property of fenofibrate as an inhibitor of CCID formation within the LEC barrier, which correlated with the inhibition of NF- $\mathrm{BB}$, the downregulation of ICAM-1 in LECs and subsequent attenuation of adhesion of cancer cells.

Almost all phosphorylation-regulated ion channels, or $\mathrm{K}^{+}$channels containing RGD sequences, may contribute to signalling networks (47) thereby modulating FAK activity. The activity of FAK is necessary for loose adhesion to the matrix and rapid directional migration $(33,34)$ as observed in CCID formation (7) and in a current study establishing the role of FAK in this process we find that knockdown of FAK substantially inhibits CCIDs (Hong et al, unpublished data). The inhibition of FAK-phosphorylation in LECs by the $\mathrm{Na}^{+}$channel inhibitor carbamazepine (48) correlates with the inhibition of CCID formation (31) and this supports the notion that also other ion channels contribute to endothelial barrier disintegration and cancer progression. To this end, it was shown that voltage gated $\mathrm{Na}^{+}$channels are differently expressed in asterocytoma and breast cancer cells $(49,50)$. Therefore, the inactivation of FAK, which was most likely achieved through the inhibition of $\mathrm{K}^{+}$-ATPase (37) was another, and NF- $\kappa \mathrm{B}$-independent mechanism of fenofibrate compromising metastatic outspread. 
Inhibition of CCID formation by combined treatment

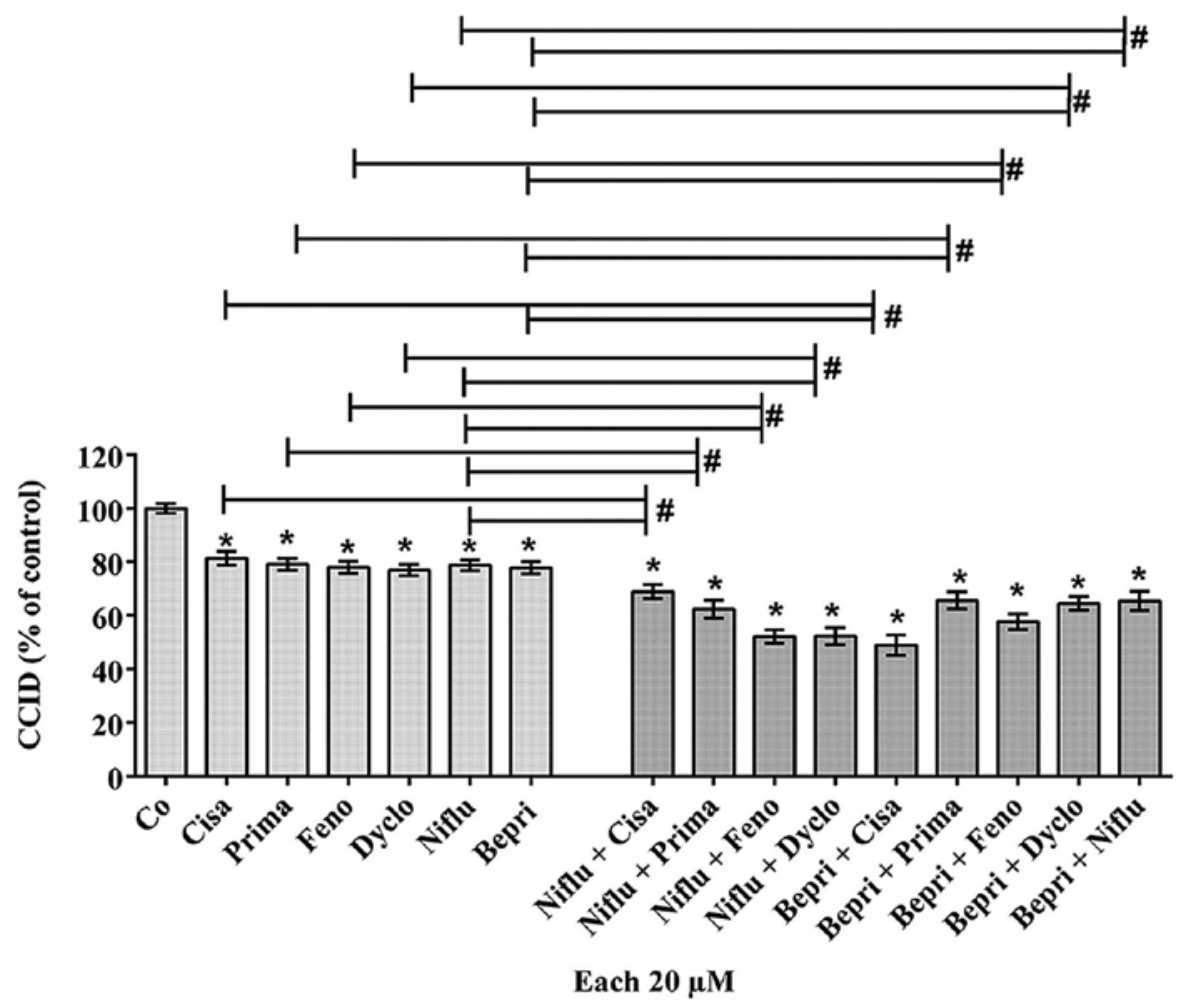

Figure 5. Analysis of drug combinations on CCID formation. MDA-MB231 spheroids were placed on LEC monolayers and treated with solvent (DMSO-Co), or with the indicated drugs (fenofibrate-Feno; cisapride-Cisa; primaquine-Prima, bepridil-Bepri; niflumic acid-Niflu; dyclonine-Dyclo), or drug combinations (solvent was kept constant) for $4 \mathrm{~h}$ when CCID areas were measured using an Axiovert microscope and Zen little 2012 software. Three independent experiments with at least 8 replicates were analysed. Error bars indicate means \pm SEM and asterisks and rhomboids significance ( $\mathrm{P}<0.05 ; \mathrm{t}$-test).

Table I. Analysis of drug combinations on CCID formation.

\begin{tabular}{lccr}
\hline Drugs & $\begin{array}{c}\text { Concentration } \\
(\mu \mathrm{M})\end{array}$ & $\begin{array}{c}\text { CCID } \\
\text { formation } \\
(\% \text { of control } \pm \mathrm{SD})\end{array}$ & $\begin{array}{r}\text { P-value } \\
\text { compared } \\
\text { to control }\end{array}$ \\
\hline Cisa & 20 & $79.97 \pm 10.60$ & $<0.0001$ \\
Prima & 20 & $81.04 \pm 9.70$ & $<0.0001$ \\
Feno & 20 & $79.21 \pm 21.85$ & 0.0089 \\
Dyclo & 20 & $81.50 \pm 13.75$ & $<0.0001$ \\
Cisa + Prima & $20 / 20$ & $84.43 \pm 21.20$ & 0.0305 \\
Cisa + Feno & $20 / 20$ & $85.51 \pm 19.31$ & 0.0309 \\
Cisa + Dyclo & $20 / 20$ & $84.85 \pm 13.23$ & 0.0006 \\
Prima + Feno & $20 / 20$ & $90.97 \pm 17.96$ & 0.0305 \\
Prima +Dyclo & $20 / 20$ & $84.75 \pm 12.32$ & 0.0009 \\
Feno + Dyclo & $20 / 20$ & $82.32 \pm 16.17$ & $<0.0001$
\end{tabular}

The effect of combination treatment versus single-drug treatment on CCID inhibition was analysed by $\mathrm{t}$-test $(\mathrm{P}<0.05$ : significant $)$.

Furthermore, the central role of $\mathrm{Ca}^{2+}$ signalling and the relevance of $\mathrm{Ca}^{2+}$ channels as central mediators and amplifiers of migration and CIDD formation in LECs and cancer associates fibroblasts $(\mathrm{CAFs})$ was reported $(8,51)$. Therefore, the $\mathrm{Ca}^{2+}$ channel inhibitor bepridil hydrochloride was tested in combination with other bona fide ion channel inhibitors. Some drug combinations improved the CCID inhibitory effect in an additive and even synergistic manner.

Whereas fenofibrate inhibited FAK activity and ICAM-1 expression in LECs, the activity of CYP1A1 was inhibited in MDA-MB231 cancercells. CYP1A1 was demonstrated to significantly contribute to breast cancer intravasation in vitro (45). CYP1A1 resides in heterogenous membrane regions of the endoplasmatic reticulum (52-54) and interactions between P450 molecules and juxtaposed proteins within the lipid layer (such as ion channels) (55) are discussed to have profound effects on CYP function (56). In fact, some studies put CYP function upstream of $\mathrm{Na}^{+}$- and $\mathrm{K}^{+}$channels demonstrating that CYP epoxigenase activity mediates arachidonic acid-triggered sodium and potassium channel inhibition $(57,58)$. Furthermore, epoxyeicosatrienoic acids, which are endothelium-derived CYP metabolites of arachidonic acid, relax vascular smooth muscle by calcium-activated potassium channel activation (59) and CYP-omega-hydroxylation-dependent metabolites inhibit $10 \mathrm{pS}$ chloride channel (60). Directionally migrating cancer cells regulate their cell volume by $\mathrm{Cl}^{-}$channels at their leading edge and inhibiting ClC-3 channel by shRNA affects glioma cell migration (61).

Nevertheless, fenofibrate-mediated inhibition of $\mathrm{K}^{+}$channels and inhibition of CYP1A1 in MDA-MB231 cells could have been entirely separate events. The comparison of MCF-7 (estrogen-dependent cell line)- and MDA-MB231 (triplenegative cell line)-based 3D models revealed differences in 
the drug activities on the inhibition of CCID formation, which can only be explained by their impact on the respective breast cancer cells but not on LECs. The mechanisms behind these differences await to be elucidated.

Besides the usage of a few anti-angiogenic therapeutics, no anti-intravasative drugs are currently available and none of the here tested drugs have been designed to inhibit malignant tumour progression. However, pharmaceutically used drugs exhibit side effects and these unintended activities might inhibit steps of the metastatic cascade. Importantly, all tested drugs are directly available to patients and the used concentrations can be reached in humans. Our new concept may lead to an improved therapy of metastasis in cancer patients.

\section{Acknowledgements}

We wish to thank Toni Jäger for preparing the figures. C.H.N was supported by technology grant (TSA Doktorat) financed by the Austria Federal Ministry of Science and Research (BMFW) in frame of Asea Uninet, A.F. was supported by DIKTI-OeAD fellowship, and J.H. by State Scholarship Fund of China Scholarship Council, the National Natural Science Foundation of China (no. 81202853) and the Natural Science Foundation of Jiangsu Province (no. BK2012444). The work was further supported by a grant of the Austrian Science Fund (FWF: S10704-B13) to V.M.D.

\section{References}

1. Sobin LH, Gospodarowicz MK and Wittekind C (eds): TNM Classification of Malignant Tumours (UICC International Union Against Cancer). 7th edition. Wiley-Blackwell, New York, 2009.

2. Vonach C, Viola K, Giessrigl B, Huttary N, Raab I, Kalt R, Krieger S, Vo TP, Madlener S, Bauer S, et al: NF- $\kappa$ B mediates the 12(S)-HETE-induced endothelial to mesenchymal transition of lymphendothelial cells during the intravasation of breast carcinoma cells. Br J Cancer 105: 263-271, 2011.

3. Viola K, Kopf S, Huttary N, Vonach C, Kretschy N, Teichmann M, Giessrigl B, Raab I, Stary S, Krieger S, et al: Bay11-7082 inhibits the disintegration of the lymphendothelial barrier triggered by MCF-7 breast cancer spheroids; the role of ICAM-1 and adhesion. Br J Cancer 108: 564-569, 2013.

4. Nguyen CH, Senfter D, Basilio J, Holzner S, Stadler S, Krieger S, Huttary N, Milovanovic D, Viola K, Simonitsch-Klupp I, et al: NF- $\mathrm{BB}$ contributes to MMP1 expression in breast cancer spheroids causing paracrine PAR1 activation and disintegrations in the lymph endothelial barrier in vitro. Oncotarget 6: 39262-39275, 2015.

5. Piwowarczyk K, Wybieralska E, Baran J, Borowczyk J, Rybak P, Kosińska M, Włodarczyk AJ, Michalik M, Siedlar M, Madeja Z, et al: Fenofibrate enhances barrier function of endothelial continuum within the metastatic niche of prostate cancer cells. Expert Opin Ther Targets 19: 163-176, 2015.

6. Madlener S, Saiko P, Vonach C, Viola K, Huttary N, Stark N, Popescu R, Gridling M, Vo NT, Herbacek I, et al: Multifactorial anticancer effects of digalloyl-resveratrol encompass apoptosis, cell-cycle arrest, and inhibition of lymphendothelial gap formation in vitro. Br J Cancer 102: 1361-1370, 2010.

7. Kerjaschki D, Bago-Horvath Z, Rudas M, Sexl V, Schneckenleithner C, Wolbank S, Bartel G, Krieger S, Kalt R, Hantusch B, et al: Lipoxygenase mediates invasion of intrametastatic lymphatic vessels and propagates lymph node metastasis of human mammary carcinoma xenografts in mouse. J Clin Invest 121: 2000-2012, 2011.

8. Nguyen CH, Brenner S, Huttary N, Li Y, Atanasov AG, Dirsch VM, Holzner S, Stadler S, Riha J, Krieger S, et al: 12(S)-HETE increases intracellular $\mathrm{Ca}(2+)$ in lymph-endothelial cells disrupting their barrier function in vitro; stabilization by clinical drugs impairing calcium supply. Cancer Lett 380: 174-183, 2016.
9. Nguyen CH, Stadler S, Brenner S, Huttary N, Krieger S, Jäger W Dolznig H and Krupitza G: Cancer cell-derived 12(S)-HETE signals via 12-HETE receptor, RHO, ROCK and MLC2 to induce lymph endothelial barrier breaching. Br J Cancer 115: 364-370, 2016.

10. Litan A and Langhans SA: Cancer as a channelopathy: Ion channels and pumps in tumor development and progression. Front Cell Neurosci 9: 86, 2015.

11. Comes N, Serrano-Albarrás A, Capera J, Serrano-Novillo C, Condom E, Ramón Y Cajal S, Ferreres JC and Felipe A: Involvement of potassium channels in the progression of cancer to a more malignant phenotype. Biochim Biophys Acta 1848: 2477-2492, 2015.

12. Northcott PA, Dubuc AM, Pfister S and Taylor MD: Molecular subgroups of medulloblastoma. Expert Rev Neurother 12: 871-884, 2012.

13. Su C, Shi A, Cao G, Tao T, Chen R, Hu Z, Shen Z, Tao H, Cao B, $\mathrm{Hu} \mathrm{D}$, et al: Fenofibrate suppressed proliferation and migration of human neuroblastoma cells via oxidative stress dependent of TXNIP upregulation. Biochem Biophys Res Commun 460: 983-988, 2015.

14. Goetze S, Eilers F, Bungenstock A, Kintscher U, Stawowy P, Blaschke F, Graf K, Law RE, Fleck E and Gräfe M: PPAR activators inhibit endothelial cell migration by targeting Akt. Biochem Biophys Res Commun 293: 1431-1437, 2002.

15. Wolle D, Lee SJ, Li Z, Litan A, Barwe SP and Langhans SA: Inhibition of epidermal growth factor signaling by the cardiac glycoside ouabain in medulloblastoma. Cancer Med 3: 1146-1158, 2014.

16. Hu X, Wei L, Taylor TM, Wei J, Zhou X, Wang JA and Yu SP: Hypoxic preconditioning enhances bone marrow mesenchymal stem cell migration via Kv2.1 channel and FAK activation. Am J Physiol Cell Physiol 301: C362-C372, 2011.

17. Wei JF, Wei L, Zhou X, Lu ZY, Francis K, Hu XY, Liu Y, Xiong WC, Zhang X, Banik NL, et al: Formation of Kv2.1-FAK complex as a mechanism of FAK activation, cell polarization and enhanced motility. J Cell Physiol 217: 544-557, 2008.

18. Bajwa PJ, Alioua A, Lee JW, Straus DS, Toro L and Lytle C: Fenofibrate inhibits intestinal $\mathrm{Cl}$ - secretion by blocking basolateral KCNQ1 K ${ }^{+}$channels. Am J Physiol Gastrointest Liver Physiol 293: G1288-G1299, 2007.

19. Shimomura K, Shimizu H, Ikeda M, Okada S, Kakei M, Matsumoto S and Mori M: Fenofibrate, troglitazone, and 15-deoxy-Delta12,14-prostaglandin J2 close KATP channels and induce insulin secretion. J Pharmacol Exp Ther 310: 1273-1280, 2004.

20. Shimomura K, Ikeda M, Ariyama Y, Proks P, Shimomura Y, Mori $M$ and Matsumoto S: Effect of peroxisome proliferatoractivated receptor alpha ligand fenofibrate on $\mathrm{K}(\mathrm{v})$ channels in the insulin-secreting cell line HIT-T15. Gen Physiol Biophys 25: 455-460, 2006.

21. De Ciuceis C, Amiri F, Iglarz M, Cohn JS, Touyz RM and Schiffrin EL: Synergistic vascular protective effects of combined low doses of PPARalpha and PPARgamma activators in angiotensin II-induced hypertension in rats. Br J Pharmacol 151: 45-53, 2007.

22. Grabacka M, Plonka PM, Urbanska K and Reiss K: Peroxisome proliferator-activated receptor alpha activation decreases metastatic potential of melanoma cells in vitro via down-regulation of Akt. Clin Cancer Res 12: 3028-3036, 2006.

23. Zhang N, Chu ES, Zhang J, Li X, Liang Q, Chen J, Chen M, Teoh N, Farrell G, Sung JJ, et al: Peroxisome proliferator activated receptor alpha inhibits hepatocarcinogenesis through mediating NF- $\mathrm{KB}$ signaling pathway. Oncotarget 5: 8330-8340, 2014.

24. Rival Y, Benéteau N, Taillandier T, Pezet M, DupontPasselaigue E, Patoiseau JF, Junquéro D, Colpaert FC and Delhon A: PPARalpha and PPARdelta activators inhibit cytokine-induced nuclear translocation of NF-kappaB and expression of VCAM-1 in EAhy926 endothelial cells. Eur J Pharmacol 435: 143-151, 2002.

25. Han D, Wei W, Chen X, Zhang Y, Wang Y, Zhang J, Wang X,

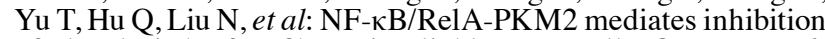
of glycolysis by fenofibrate in glioblastoma cells. Oncotarget 6 : 26119-26128, 2015.

26. Chandran K, Goswami S and Sharma-Walia N: Implications of a peroxisome proliferator-activated receptor alpha (PPAR $\alpha)$ ligand clofibrate in breast cancer. Oncotarget 7: 15577-15599, 2016.

27. Abu Aboud O, Wettersten HI and Weiss RH: Inhibition of PPAR $\alpha$ induces cell cycle arrest and apoptosis, and synergizes with glycolysis inhibition in kidney cancer cells. PLoS One 8: e71115, 2013. 
28. Huang WP, Yin WH, Chen JW, Jen HL, Young MS and Lin SJ: Fenofibrate attenuates endothelial monocyte adhesion in chronic heart failure: An in vitro study. Eur J Clin Invest 39: 775-783, 2009.

29. Tsai SC, Tsai MH, Chiu CF, Lu CC, Kuo SC, Chang NW and Yang JS: AMPK-dependent signaling modulates the suppression of invasion and migration by fenofibrate in CAL 27 oral cancer cells through NF-кB pathway. Environ Toxicol 31: 866-876, 2016.

30. Koh KK, Oh PC, Sakuma I, Lee Y, Han SH and Shin EK: Vascular and metabolic effects of omega-3 fatty acids combined with fenofibrate in patients with hypertriglyceridemia. Int $\mathrm{J}$ Cardiol 221: 342-346, 2016

31. Teichmann M, Kretschy N, Kopf S, Jarukamjorn K, Atanasov AG, Viola K, Giessrigl B, Saiko P, Szekeres T, Mikulits W, et al: Inhibition of tumour spheroid-induced prometastatic intravasation gates in the lymph endothelial cell barrier by carbamazepine: Drug testing in a 3D model. Arch Toxicol 88: 691-699, 2014

32. Rozema E, Atanasov AG, Fakhrudin N, Singhuber J, Namduang U, Heiss EH, Reznicek G, Huck CW, Bonn GK, Dirsch VM, et al: Selected extracts of Chinese herbal medicines: Their effect on NF- $\mathrm{NB}, \mathrm{PPAR} \alpha$ and PPAR $\gamma$ and the respective bioactive compounds. Evid Based Complement Alternat Med 2012: 983023, 2012

33. Gu J, Tamura M, Pankov R, Danen EH, Takino T, Matsumoto K and Yamada KM: Shc and FAK differentially regulate cell motility and directionality modulated by PTEN. J Cell Biol 146 : 389-403, 1999.

34. Wang HB, Dembo M, Hanks SK and Wang Y: Focal adhesion kinase is involved in mechanosensing during fibroblast migration. Proc Natl Acad Sci USA 98: 11295-11300, 2001

35. Cherniavsky Lev M, Karlish SJ and Garty H: Cardiac glycosides induced toxicity in human cells expressing $\alpha 1-, \alpha 2-$, or $\alpha 3$-isoforms of Na-K-ATPase. Am J Physiol Cell Physiol 309: C126-C135, 2015.

36. Rodrigues-Mascarenhas S, Da Silva de Oliveira A, Amoedo ND, Affonso-Mitidieri OR, Rumjanek FD and Rumjanek VM: Modulation of the immune system by ouabain. Ann NY Acad Sci 1153: 153-163, 2009.

37. Pongrakhananon V, Chunhacha $\mathrm{P}$ and Chanvorachote P: Ouabain suppresses the migratory behavior of lung cancer cells. PLoS One 8: e68623, 2013.

38. Lin SY, Chang HH, Lai YH, Lin CH, Chen MH, Chang GC, Tsai MF and Chen JJ: Digoxin suppresses tumor malignancy through inhibiting multiple Src-related signaling pathways in non-small cell lung cancer. PLoS One 10: e0123305, 2015.

39. Walker BD, Singleton CB, Bursill JA, Wyse KR, Valenzuela SM, Qiu MR, Breit SN and Campbell TJ: Inhibition of the human ether-a-go-go-related gene (HERG) potassium channel by cisapride: Affinity for open and inactivated states. Br J Pharmacol 128: 444-450, 1999.

40. Kim KS, Lee HA, Cha SW, Kwon MS and Kim EJ: Blockade of hERG $\mathrm{K}(+)$ channel by antimalarial drug, primaquine. Arch Pharm Res 33: 769-773, 2010.

41. McFerrin MB and Sontheimer $\mathrm{H}$ : A role for ion channels in glioma cell invasion. Neuron Glia Biol 2: 39-49, 2006.

42. Cruickshank SF, Baxter LM and Drummond RM: The Cl(-) channel blocker niflumic acid releases $\mathrm{Ca}(2+)$ from an intracellular store in rat pulmonary artery smooth muscle cells. Br J Pharmacol 140: 1442-1450, 2003.

43. Sahdeo S, Scott BD, McMackin MZ, Jasoliya M, Brown B, Wulff H, Perlman SL, Pook MA and Cortopassi GA: Dyclonine rescues frataxin deficiency in animal models and buccal cells of patients with Friedreich's ataxia. Hum Mol Genet 23: 6848-6862, 2014.

44. Flaim SF, Ratz PH, Swigart SC and Gleason MM: Bepridil hydrochloride alters potential-dependent and receptor-operated calcium channels in vascular smooth muscle of rabbit aorta. J Pharmacol Exp Ther 234: 63-71, 1985.

45. Nguyen $\mathrm{CH}$, Brenner S, Huttary N, Atanasov AG, Dirsch VM, Chatuphonprasert W, Holzner S, Stadler S, Riha J, Krieger S, et al: AHR/CYP1A1 interplay triggers lymphatic barrier breaching in breast cancer spheroids by inducing 12(S)-HETE synthesis. Hum Mol Genet: Sep 27, 2016 (Epub ahead of print).
46. Burgazli KM, Venker CJ, Mericliler M, Atmaca N, Parahuleva M and Erdogan A: Importance of large conductance calciumactivated potassium channels (BKCa) in interleukin-1b-induced adhesion of monocytes to endothelial cells. Eur Rev Med Pharmacol Sci 18: 646-656, 2014.

47. McPhee JC, Dang YL, Davidson N and Lester HA: Evidence for a functional interaction between integrins and $\mathrm{G}$ protein-activated inward rectifier K+ channels. J Biol Chem 273: 34696-34702, 1998.

48. Camerino DC, Tricarico D and Desaphy JF: Ion channel pharmacology. Neurotherapeutics 4: 184-198, 2007.

49. Driffort V, Gillet L, Bon E, Marionneau-Lambot S, Oullier T, Joulin V, Collin C, Pagès JC, Jourdan ML, Chevalier S, et al: Ranolazine inhibits NaV1.5-mediated breast cancer cell invasiveness and lung colonization. Mol Cancer 13: 264, 2014

50. Brisson L, Driffort V, Benoist L, Poet M, Counillon L, Antelmi E, Rubino R, Besson P, Labbal F, Chevalier S, et al: NaV1.5 Na channels allosterically regulate the NHE-1 exchanger and promote the activity of breast cancer cell invadopodia. J Cell Sci 126: 4835-4842, 2013

51. Stadler S, Nguyen CH, Schachner H, Milovanovic D, Holzner S, Brenner S, Eichsteininger J, Stadler M, Senfter D, Krenn L, et al: Colon cancer cell-derived 12(S)-HETE induces the retraction of cancer-associated fibroblast via MLC2, RHO/ROCK and $\mathrm{Ca}^{2+}$ signalling. Cell Mol Life Sci: Dec 24, 2016 (Epub ahead of print).

52. Park JW, Reed JR, Brignac-Huber LM and Backes WL: Cytochrome $\mathrm{P} 450$ system proteins reside in different regions of the endoplasmic reticulum. Biochem J 464: 241-249, 2014

53. Park JW, Reed JR and Backes WL: The Localization of cytochrome P450s CYP1A1 and CYP1A2 into different lipid microdomains is governed by their N-terminal and internal protein regions. J Biol Chem 290: 29449-29460, 2015.

54. Brignac-Huber L, Reed JR and Backes WL: Organization of NADPH-cytochrome P450 reductase and CYP1A2 in the endoplasmic reticulum - microdomain localization affects monooxygenase function. Mol Pharmacol 79: 549-557, 2011.

55. Berka K, Paloncýová M, Anzenbacher P and Otyepka M Behavior of human cytochromes P450 on lipid membranes. J Phys Chem B 117: 11556-11564, 2013.

56. Scott EE, Wolf CR, Otyepka M, Humphreys SC, Reed JR, Henderson CJ, McLaughlin LA, Paloncýová M, Navrátilová V, Berka K, et al: The role of protein-protein and protein-membrane interactions on P450 function. Drug Metab Dispos 44: 576-590, 2016.

57. Wei Y, Lin DH, Kemp R, Yaddanapudi GS, Nasiletti A, Falck JR and Wang WH: Arachidonic acid inhibits epithelial Na channel via cytochrome P450 (CYP) epoxygenase-dependent metabolic pathways. J Gen Physiol 124: 719-727, 2004.

58. Wang Z, Wei Y, Falck JR, Atcha KR and Wang WH: Arachidonic acid inhibits basolateral $\mathrm{K}$ channels in the cortical collecting duct via cytochrome P-450 epoxygenase-dependent metabolic pathways. Am J Physiol Renal Physiol 294: F1441-F1447, 2008.

59. Campbell WB, Holmes BB, Falck JR, Capdevila JH and Gauthier KM: Regulation of potassium channels in coronary smooth muscle by adenoviral expression of cytochrome P-450 epoxygenase. Am J Physiol Heart Circ Physiol 290: H64-H71, 2006.

60. Gu RM, Yang L, Zhang Y, Wang L, Kong S, Zhang C, Zhai Y, Wang M, Wu P, Liu L, et al: CYP-omega-hydroxylationdependent metabolites of arachidonic acid inhibit the basolateral $10 \mathrm{pS}$ chloride channel in the rat thick ascending limb. Kidney Int 76: 849-856, 2009

61. Cuddapah VA and Sontheimer H: Molecular interaction and functional regulation of $\mathrm{ClC}-3$ by $\mathrm{Ca}^{2+} /$ calmodulin-dependent protein kinase II (CaMKII) in human malignant glioma. J Biol Chem 285: 11188-11196, 2010. 